|| ISSN(online): 2589-8698 || ISSN(print): 2589-868X || International Journal of Medical and Biomedical Studies

Available Online at www.ijmbs.info

PubMed (National Library of Medicine ID: 101738825)

Index Copernicus Value 2017: 40.03

Volume 3, Issue 3; March: 2019; Page No. 31-34

\title{
ACCIDENTAL INTRA-ORAL INJECTION OF XYLENE INSTEAD OF LOCAL ANESTHETIC AGENT IN ENDODONTIC RETREATMENT
}

\author{
Sonu Acharya ${ }^{1}$, Dipmalla Sahoo ${ }^{1}$, Faizan Qamar ${ }^{1}$, Sarjana Mishra ${ }^{1}$, Ankita Sinha $^{1}$ \\ ${ }^{1}$ Department of Pedodontics and Preventive Dentistry, Institute of Dental Sciences, SOA Deemed to be \\ University, Bhubaneswar, Odisha
}

Article Info: Received 10 January 2019; Accepted 26 February. 2019

Cite this article as: Acharya, S., Sahoo, D., Qamar, F., Mishra, S., \& Sinha, A. (2019). ACCIDENTAL INTRA-ORAL INJECTION OF XYLENE INSTEAD OF LOCAL ANESTHETIC AGENT IN ENDODONTIC RETREATMENT. International Journal of Medical and Biomedical Studies, 3(3).

DOI: https://doi.org/10.32553/ijmbs.v3i1.140

Address for Correspondence: Prof.(Dr.)Sonu Acharya, HIG-48, Phase 1,7 acres, Housing Board, colony, Chandrasekharpur, Bhubaneswar, Odisha-751016

Conflict of interest: No conflict of interest.

\section{Abstract}

There have been quite a few case reports of organic solvents accidentally being injected into the oral cavity during dental procedures. These solvents, which should be used with caution mostly, are clear liquids which get confused with local anesthetic solutions when not kept in proper container and thus accidents happen. There have been reports of sodium hypochlorite, chloroform being pushed as local anesthetic solution in the oral cavity. In a first of its kind report, here we discuss the accidental intraoral injection of xylene being used for guttapercha solvent instead of local anesthetic agent and its management.

Keywords: Accidental, injection, oral, solvent, Xylene

\section{Introduction:}

Xylene is an aromatic hydrocarbon known for its wide usage in tissue processing, staining and cover slipping in the histology laboratory. It is a colorless, sweet-smelling liquid or gas occurring naturally in petroleum, coal and wood tar, and is so named because it is found in crude wood spirit (Gr. xy'lon- wood). ${ }^{1}$ It has a chemical formula of $\mathrm{C} 6 \mathrm{H} 4(\mathrm{CH} 3) 2$ and is referred to as "dimethyl benzene" because it consists of a sixcarbon ring to which two methyl groups are bound. It exists in three isomeric forms: ortho-, meta- and para-xylene. ${ }^{2}$ In dentistry, xylene is used in histological laboratories for tissue processing, staining and cover slipping and also in endodontic retreatment as a guttapercha solvent. Its high solvency factor allows maximum displacement of alcohol and renders the tissue transparent, enhancing paraffin infiltration. In staining procedures, its excellent dewaxing and clearing capabilities contribute to brilliantly stained slides. The National Institute for Occupational Safety and Health recommended exposure limits for xylene at $100 \mathrm{ppm}$ as a TWA for up to a 10-h work shift and a 40-h work week and 200 ppm for $10 \mathrm{~min}$ as a short-term limit. ${ }^{2,3}$

There has been massive growth in endodontic treatment in recent years. This increase in clinical activity can be attributable to better-trained dentists and specialists alike. Necessary for this unfolding story is the general public's growing selection for root canal treatment as an alternative to the extraction. Inspite of the use of technological advances and eqipment, there remains a chance for endodontic failure.. Root 
canal system anatomy plays a significant role in endodontic success and failure. These systems contain branches that communicate with the periodontal attachment apparatus furcally, laterally, and often terminate apically into multiple portals of exit. Endodontic failures can be attributable to inadequacies in shaping, cleaning and obturation, iatrogenic events, or reinfection of the root canal system when the coronal seal is lost after completion of root canal treatment. ${ }^{4}$ The dental science has made a rapid progress and now the focus is to save the tooth, if restorable at any cost. The need of the hour is retreatment in endodontic failures rather than extraction. ${ }^{5}$ Here we discuss a rare case where during retreatment of root canal treated tooth xylene which was to be used as gutta percha solvent was given instead of local anesthesia for pain control. This is the first reported case to our knowledge where xylene was given accidentally in lieu of local anesthetic solution.

\section{Case report}

A thirteen years old male child reported to the outpatient department of pedodontics and preventive dentistry with a complain of pain in the upper front teeth. There was a slight swelling associated with the upper central incisors in the labial mucosa. The central incisors were tender on percussion. The parents gave history of root canal treatment being done on both central incisors one year ago. Intra-oral peri apical radiographs were advised and they revealed poorly obturated canals and peri apical radiolucency in both central incisors. The parents wanted the teeth to be saved as they were concerned about the esthetics of the child. The teeth were evaluated and after discussion with parents it was scheduled for endodontic retreatment. As the patient was not allowing to touch the teeth it was decided to do the procedure under local anesthesia .For removal of gutta percha from canals, xylene was supposed to be used. The local anesthetic agent was injected $(1.5 \mathrm{ml})$ for pain control so that the procedure could be done painlessly. While waiting for the anesthetic agent to work the patient complained of increased pain. The pain gradually increased and the patient started crying. Till that time we were unaware of what has happened. It occured to us, that the attendant could have handed over the syringe containing xylene to the practitioner. There might have been an error on the part of attendant while giving the solution of local anesthetic agent. The pain had increased in severity. The patient was made to calm down along with the anxious parents. There was not a single mention in literature of xylene being given instead of local anesthetic agent. The mishap was discussed with senior faculties of pedodontia (author), general medicine and oral surgery. The medicine specialists advised to give analgesic and steroids immediately and the oral surgeons advised for local anesthesia of the region for pain control. After thorough discussions, we gave dexamethasone (Decadron $0.25 \mathrm{mg}$ i.m) along with diclofenac sodium .The pain subsided immediately after giving local anesthesia in the region. All the vitals were normal. Isotonic saline was injected in the region of nerve block using a large bore needle (18 gauge) and the content was aspirated. The maneuver was repeated for several times to eliminate the xylene from the tissue spaces. Medications prescribed were 1) Amoxycillin with potassium clavunate (625mg) twice daily.2) Metronidazole (200mg) thrice daily.3) Trypsin, bromelain, rutoside and diclofenac combination twice daily.4) oral dexamethasone (5mg)twice daily for five days. The patient reported after 24 hours with a large swelling with the skin becoming purple in colour. Pain was not severe. Patient and parents were reassured and recalled after five days with advice to report immediately if pain increased before 5 days. After three days patient complained of excruciating pain and came to department. It was decided to drain the swelling and a stab incision was given at the most dependent part of swelling intra-orally. The wound showed necrosis of tissue and lot of purulent discharge was seen.. Complete cleaning with saline and povidone-iodine was done and a corrugated rubber drain was placed for further 
drainage. The patient was recalled after 4 days and drain was removed. Swelling had subsided but not to much extent. The parents meanwhile were very agitated all throughout the course of treatment and never allowed to take any pictures during or after the treatment. The antibiotics, analgesics and enzymes were continued for 14 days. The steroids also were given for 10 days and then tapered. The pain subsided once the drainage was done .Regular recalls (every three days) were advised and it took 25 days for complete healing.
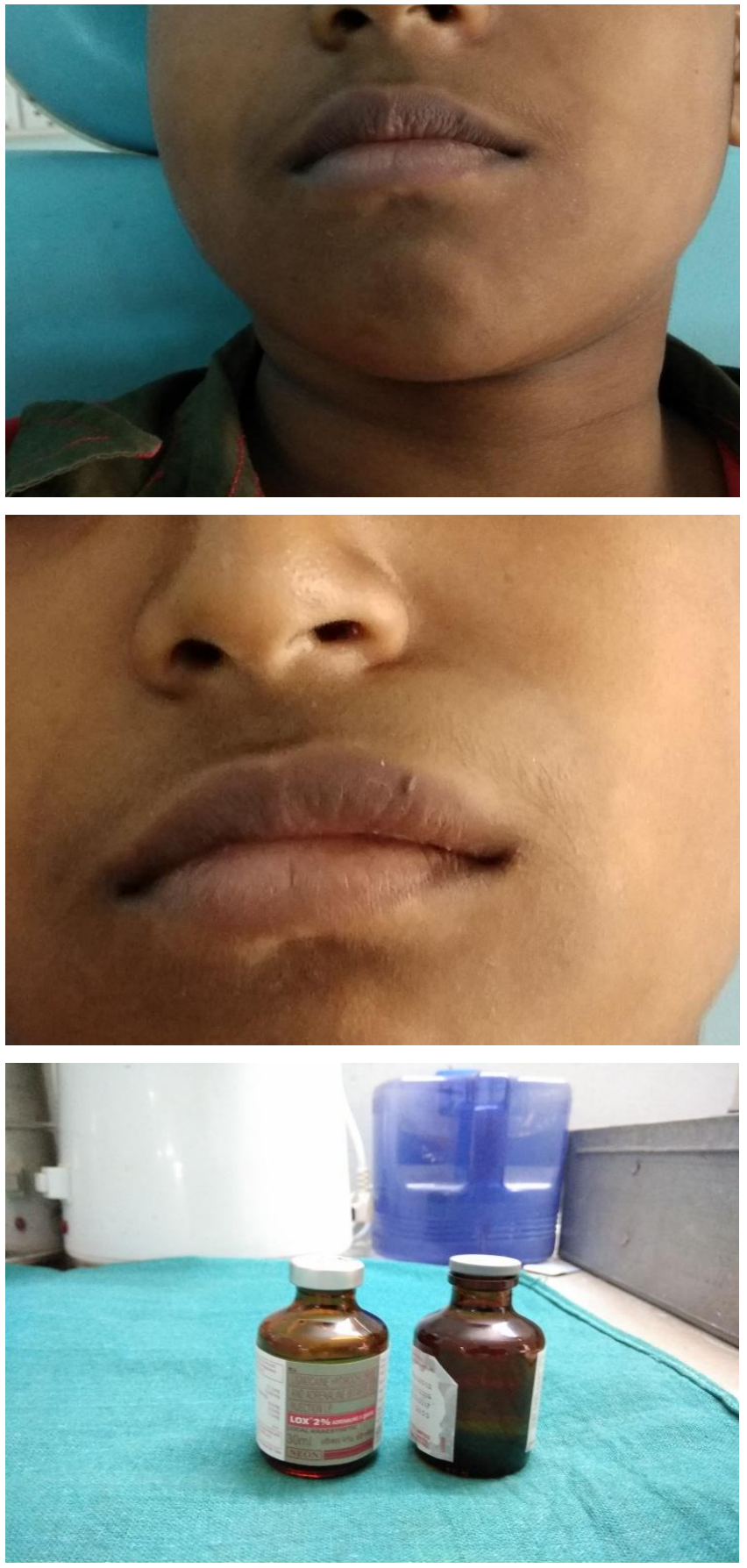

\section{Discussion}

In dentistry, xylene is used in histological laboratories for tissue processing, staining and cover slipping and also in endodontic retreatment as a guttapercha solvent. ${ }^{6}$ Accidental injury from dental chemicals may occur with a number of substances like formalin, sodium hypochlorite. ${ }^{7,8,9,10}$ Formalin being a tissue preservative and sodium hypochlorite being an irrigant in endodontic procedures. ${ }^{11}$ Xylene is used as a gutta percha solvent for retreatment in root canal treatment. ${ }^{5}$ There have been reports of inadvertent injections of sodium hypochlorite in the oral region during endodontic procedures. ${ }^{12,13}$ These cases, although deplorable, provide a unique chance to study the effect of such corrosive chemicals on the maxillofacial region and also contributes towards the available body of literature regarding the best possible management of the patient, if such a case be ever encountered. Although no laid down guidelines exist about the management of patients with intra-oral injections of corrosive substances but palliative treatment are must as well as follow up. ${ }^{14}$ In a dental setting especially, several colorless chemicals like normal saline, formalin, hydrogen peroxide, sodium hypochlorite are often simultaneously used, thereby necessitating proper labeling and separate storage and shelving for each one. In general, local anesthetic solution should be kept away from such corrosive chemicals. Another major issue, especially in India, is the use of untrained dental assistants. ${ }^{15}$ The practicing clinicians should always double check before injecting any solution in the oral cavity so as to prevent any untoward incident like the one happened here. These precautions might help to some extent in avoiding such mishaps in the dental office. After the careful scrutiny of existing literature on management of accidental injection of corrosive liquids into peri-oral tissue spaces, we found that aspiration of injected content followed by systemic antibiotic therapy with early intramuscular corticosteroid administration is crucial in preventing any further complication. The most important fact to be kept 
in mind is to remain calm, not to panic. The patient as well as parents also has to be reassured. The case reported here is the first to be reported with xylene as the culprit solution. The management was the same as for other corrosive agents but here it has to be kept in mind that tissue necrosis and pain will be severe along with swelling. It took almost a month for healing and swelling to subside. We have noted that use of steroids and enzymes (trypsin, bromelain, rutoside) along with timely intervention with local anesthetic and analgesics saved the day for as these medications checked the pain and swelling to a large extent.

\section{Conclusion}

The clinicians should take utmost care in each step when treatment is being done on a patient and should cross check all the solutions being given by assistants for use in patients. Otherwise there are complications to be faced which can be life threatening to the patient.

\section{References}

1. Toxicological profile for xylene, U.S Department of Health and Human Services, public health service, Agency for toxic substance and disease registry. 1993

2. OSHA (Occupational safety and health administration) 2005 Air contaminants Occupational Safety and Health Administration. Available from: http:// www. osha.gov/comp-links.html [last cited on 2009 Dec 16]

3. National Institute for Occupational Safety and Health (NIOSH) criteria for a recommended standard: Occupational exposure to xylene 1975. Available from: http://www.cdc.gov/niosh/75-168. html [last cited on 2009 Dec 16]

4. Ingle JI, Bakaland LK. Outcome of endodontic treatment and retreatment: Endodontics. 5th ed. Hamilton: BC Decker Inc; 2002. pp. 747-68.

5. Wourms DJ, Campbell AD, Hicks ML, Pelleu GB. Alternative solvents to chloroform for gutta-percha removal. J Endod.1990;16:224 $-6$

6. Martos J, Gastal MT, Sommer L, Lund RGL, Del Pino FAB, Osinaga PWR. Dissolving efficacy of organic solvents on root canal sealers. Clin Oral Invest. 2006;10(1):50-4

7. Lian CB, Ngeow WC. The adverse effect of formalin: a warning against mishandling. Ann Dentistry2000;7:56-8.

8. Durga SG, Shilpi S, Padam NT, et al. Formalin-induced iatrogenic cellulitis: a rare case of dental negligence.J Oral Maxillofac Surg 2011;69:e525-7

9. Arakeri G, Brennan PA. Inadvertent injection of formalin mistaken for local anesthetic agent: Report of a case. Oral Surg Oral Med Oral Pathol Oral Radiol. 2012;113:581-82

10. Reeh ES, Messer HH. Long-term paraesthesia following inadvertent forcing of sodium hypochlorite through a perforation in maxillary incisor. Endod Dent Traumatol. 1989;5:200-203.

11. Hales JJ, Jackson CR, Everett AP, Moore SH. Treatment protocol for the management of a sodium hypochlorite accident during endodontic therapy. Gen Dent. 2001;49: 278-281.

12. Witton R, Brennan PA. Severe tissue damage and neurological deficit following extravasation of sodium hypochlorite solution during routine endodontic treatment. Br Dent J. 2005;198:749-750.

13. J. J. Hales, C. R. Jackson, A. P. Everett, and S. H. Moore, "Treatment protocol for the management of a sodium hypochlorite accident during endodontic therapy," General dentistry, vol. 49, no. 3, pp. 278281, 2001

14. Dandriyal R, Giri KY, Alam S, Singh AP. Accidental intraoral formalin injection: a rare case report. Clin Pract 2014;4:686

15. Rooban $T$, Rao UK, Joshua E, Ranganathan $K$. Survey of responsible handling of local anesthetic in Indian dental operatory. J Forensic Dent Sci. 2013;5:138-45. 